\section{Memórias do jornalismo na Bahia: censura, conflitos e o surgimento da Associação Bahiana de Imprensa na década de 1930}

\author{
Hérica LENE (UFRB) ${ }^{1}$ \\ Rafael LOPES (UFRB) ${ }^{2}$
}

Resumo: Este artigo tem como objetivo resgatar parte da memória e da história da imprensa na Bahia, especificamente da Associação Bahiana de Imprensa (ABI). A pesquisa que o originou envolveu levantamento bibliográfico sobre metodologias de pesquisa em comunicação, história da imprensa na Bahia, sobre a $\mathrm{ABI}$, teorias do jornalismo e memória; realização de entrevistas com membros da Associação (presidentes e ex-presidentes); visita ao acervo da ABI para análise do clipping de publicações na imprensa baiana sobre essa organização. Há poucas publicações sobre as associações de imprensa existentes no país. Assim, esta abordagem se justifica no sentido de buscar entender o papel de instituições do tipo para a categoria dos jornalistas, no que concerne aos valores imbricados na identidade profissional, e para os estudos do campo de História da Comunicação.

Palavras-chave: Comunicação; Memória e História da Imprensa; História da Comunicação; Associação Bahiana de Imprensa;

\section{Recuerdos de periodismo en Bahía: la censura, los conflictos y la aparición la}

1 Doutora em Comunicação e Cultura pela UFRJ (2009), mestre em Comunicação pela UFF (2004) e professora do curso de Comunicação da UFRB. E-mails: hericalene@pesquisador.cnpq.br e hericalene@yahoo.com.br.

2 Graduado em Jornalismo pela UFRB. Desenvolveu uma pesquisa de iniciação científica sobre a Associação Bahiana de Imprensa. Email: raufis@gmail.com.
Asociación de la Prensa de Bahía, en la década de 1930

Resumen: Este artículo pretende recuperar parte de la memoria y la historia de la prensa en Bahía, específicamente la Asociación de Prensa de Bahía (ABI). La investigación que se originó involucrados encuesta bibliográfica de los métodos de investigación en comunicación, historia de la imprenta en Bahía, en el ABI, las teorías del periodismo y de la memoria; entrevistas con miembros de la Asociación (presidentes y ex presidentes); visita a la colección de recortes ABI para el análisis de las publicaciones en la prensa bahiana sobre esta organización. Pocas publicaciones sobre las asociaciones de prensa existente en el país. Por lo tanto, este enfoque se justifica en la búsqueda para entender el papel de las instituciones de cualquier tipo para la categoría de los periodistas, con respecto a los valores entrelazadas en la identidad profesional, y el campo de estudio de Historia de la Comunicación.

Palabras clave: Comunicación; Memoria e Historia de Prensa; Historia de la Comunicación; Asociación de la Prensa de Bahía.

\section{Introdução}

Há 85 anos, um grupo de 73 jornalistas se reuniu em Salvador para fundar a Associação Bahiana de Imprensa (ABI), no dia 17 de agosto de 1930. No Rio de Janeiro, já havia sido criada a Associação Brasileira de Imprensa (ABI), em 7 de abril de 1908, idealizada pelo jornalista catarinense Gustavo de Lacerda (LENE, 2013). Foi fundada em uma época de transformações da imprensa, que vai substituindo a produção artesanal dos impressos, com a incorporação dos avanços técnicos, por processos de caráter industrial, dentro do contexto histórico daquele início de século. ${ }^{3}$

É nesse bojo de modernização da imprensa que surgiu a ABI nacional. A organização que visaria agrupar 3 A fase compreendida entre o último quartel do século XIX e o início do seguinte é considerada como um período de inflexão na trajetória da imprensa brasileira. Máquinas modernas de composição mecânica e rotativas cada vez mais velozes alteraram o processo de compor e reproduzir textos e imagens, e passaram a ser utilizadas pelos periódicos de algumas das principais capitais brasileiras. Se, por várias décadas, a luta política constitui-se no motor fundamento do jornal, o foco passou a ser o negócio, o aumento de tiragem e do número de páginas e da oferta de uma mercadoria mais atraente. Esse contexto foi marcado pelo final da escravidão, instauração do regime republicano e seu ideal de reformar o ensino e disseminar o letramento, prosperidade trazida pelo café, crescimento dos centros urbanos e do setor de serviços, com particular destaque para o Rio de Janeiro e São Paulo (LUCA, 2008, p. 150). 
os jornalistas decorreu do desenvolvimento da imprensa, da importância que ela conquistara e das novas condições que se apresentavam, peculiares à imprensa industrial, nas grandes cidades. "Atingida a etapa da grande imprensa, estabelecida esta em moldes capitalistas, surgiria, necessariamente, a organização agrupadora dos que nela trabalhavam, os profissionais, os jornalistas" (SODRÉ, 1999, p.307).

E, tendo uma associação de jornalistas com pretensões nacionais como a ABI, por que há necessidade de criação de uma entidade semelhante no Estado da Bahia? Como e por que surge na década de 1930? Qual o papel que a $\mathrm{ABI}$ desempenhou para o jornalismo (imprensa e categoria) no Estado? Quais foram os fatos marcantes da memória e trajetória dessa instituição? Qual seu papel diante de um jornalismo que enfrenta desafios com as novas tecnologias da informação e da comunicação?

Ainda há poucas publicações específicas sobre a história da imprensa na Bahia. Sobre a ABI especificamente, há três livros que são de autoria da própria instituição: uma cronologia, outro faz menção ao objetivo geral da ABI "que é a defesa da liberdade de imprensa", e o último é sobre a gestão da diretoria (biênio 20112012). Assim, espera-se contribuir com esta abordagem ${ }^{4}$ para um resgate histórico dessa instituição, inserida no contexto da imprensa do Estado.

Esta pesquisa envolveu uma reflexão sobre o contexto comunicacional na década de 1930 e suas interfaces, levando-se em conta os fatores históricos, políticos, econômicos e culturais dessa fase. O campo do contexto comunicacional implica sempre situar os processos comunicativos em perspectivas e conjunturas históricas, sociais e culturais (SANTAELLA, 2002, p. 100).

Os seguintes procedimentos metodológicos foram utilizados: levantamento bibliográfico sobre metodologias de pesquisa em comunicação, sobre história da imprensa na Bahia, sobre a ABI, teorias do jornalismo e memória; realização de entrevistas com membros da Associação (presidentes e ex-presidentes) e jornalistas baianos; visitas ao acervo da ABI para análise do clipping de publicações na imprensa baiana sobre a instituição.

Ao buscar os depoimentos, levamos em conta que as lembranças, apesar de pertencerem aos indivíduos, se originam na sociedade. Os sujeitos só lembram a partir do ponto de vista de um grupo social específico, ao qual de alguma forma se vinculam (HALBWACHS, 1990). Memória é experiência vivida, configurada pela

4 Esta abordagem fez parte do projeto Memória e História da Imprensa, desenvolvido no Grupo de Pesquisa "Comunicação, identidades e memória" do curso de Jornalismo da UFRB. Incluiu realização de pesquisas dentro da área de História da Comunicação. dialética lembrança e esquecimento, lugares de disputas, conflitos, na busca incessante por sentidos coerentes e unívocos (NORA, 1993).

É um processo de ordenamento, de produção de sentido, que pressupõe enquadramentos, esquecimentos e silêncios. Fatos e aspectos do passado são recordados e enfatizados a partir da relevância que eles têm para os indivíduos que recordam pela sua contribuição na construção da identidade e das relações pessoais (POLLAK, 1989).

O ponto de partida de qualquer ato mnemônico é o presente. A memória, por ser essencialmente discurso, é sempre contextual e dialógica. A sua organização está ligada a processos de seleção e enquadramento, resultantes de conflitos e negociações que os sujeitos travam em situações sociais concretas. Assim, os relatos dos ex-presidentes da ABI fazem um processo de ordenamento dos principais fatos que eles consideram como importantes para a construção da história da instituição.

\section{O contexto nacional e regional dos anos 1930}

No Brasil, a década de 1930 foi marcada por transformações políticas e sociais. Foi um ano de disputa eleitoral, no qual o presidente paulista Washington Luís (eleito em 1926) foi remanejado do seu cargo por romper com a política café-com-leite (uma política de revezamento de partido) ao indicar o governador de São Paulo, Júlio Prestes, como seu sucessor.

A partir deste período inicia-se a chamada "revolução. Com o rompimento das oligarquias, forma-se uma chapa de oposição, composta por membros políticos de Minas Gerais, Rio Grande do Sul e Rio Grande do Norte. Compondo a chamada "Aliança Liberal, que lançou o nome de Getúlio Vargas para a presidência, competindo assim com Júlio Prestes. Assumindo o posto de grupos oponentes às oligarquias, os liberais contaram logo com o apoio urbano (SKIDMORE, 2003, p.153158).

A Revolução de 1930 foi a saída que as classes sociais dominantes no Brasil encontraram para superar a estagnação do sistema oligárquico que lhes servira nos 41 anos anteriores. Havia insatisfação nas camadas sociais médias dos grandes centros urbanos, levantes militares, conspirações permanentes de políticos e militares, repetidas greves de operários industriais e trabalhadores, estados ameaçando separar-se do conjunto federativo, e coronéis fortalecidos nos seus municípios e áreas de domínio (TAVARES, 2008, p.380).

Antes da revolução, houve a eleição presidencial com a sedução da campanha da Aliança Liberal divul- 
gando palavras de ordem de combate às oligarquias, voto universal e secreto, leis trabalhistas e reforma agrária gradativa.

Não fosse pela atividade conspirativa de alguns poucos militares e civis, a Revolução de 1930 teria chegado à Bahia como surpresa ainda maior (TAVARES, 2008, p.381). Isso porque o grupo político que há seis anos era dominante no Estado ${ }^{5}$ era comprometido com o governo Washington Luís. Esse grupo não só apoiou a candidatura oficial do governador paulista à Presidência da República como negociou a vice-presidência para o governador Vital Henriques Batista Soares. Em razão dessas combinações típicas do sistema oligárquico brasileiro, os Calmons e as facções e indivíduos no poder fecharam a Bahia para a campanha da Aliança Liberal.

Mesmo tendo um grande apoio em outros estados, a Aliança liberal acabou perdendo para as oligarquias pelo motivo do sistema de favores, fraudes e indicações que era composto o cenário eleitoral. Apesar de algumas tentativas de denunciar as irregularidades e buscando acordo, Getúlio Vargas e seus aliados já estavam praticamente derrotados pelas forças das oligarquias.

Houve o assassinato de João Pessoa (vice de Vargas), que acabou servindo de protesto para a organização da Revolução de 1930, movimento que ocorre ao mesmo tempo em vários estados do país. Em um período de um mês, os tenentes e apoiadores conseguiram impor e retirar Washington Luís do poder levando Vargas ao governo presidencial (SKIDMORE, 2003, p.153-158).

E ele inicia um novo modo de governo altamente centralizado e monolítico; um modelo que proporciona uma maior autonomia para a sociedade política instituindo mecanismos para o fortalecimento do poder do Estado e aperfeiçoamento das formas de controle.

A "Era Vargas" trouxe um ideal centralizador composto por cerceamentos às liberdades individuais interferindo, assim, em todas as esferas do país, sobretudo a imprensa. Ele montou um complexo quadro jurídico-institucional, criando mecanismos para interferir nos diversos setores da vida social e ampliar os poderes do Executivo, construindo normas reguladoras nas relações entre o poder central e o estadual (restringindo a autonomia dos governos estaduais), instituindo instrumentos de intervenção na economia e de controle político e criando uma estrutura corporativa, onde se sentiam aparentemente incluídos os diferentes grupos sociais, entre eles

5 Era composto do ex-governador Francisco Marques de Góes Calmon e seus irmãos, Antônio e Miguel Calmon di Pin e Almeida, correligionários, aderentes e os aliados mais próximos, os dissidentes do seabrismo e Otávio Mangabeira, na época ministro do Exterior (TAVARES, 2008, p.381). os trabalhadores urbanos (FAUSTO, 1986, apud BARBOSA, 2007, p. 106).

A revolução de 1930 encontrou as empresas jornalísticas executando programas de expansão editorial em todo o país, e não só nas maiores capitais (BAHIA, 2009, p.200). Ao se instalar no Palácio do Catete, Vargas contava com os aplausos dos vários jornais de Assis Chateaubriand, do Correio da Manhã, O Globo, Jornal do Commercio, Diário Carioca, Diário de Notícias, O Estado de S.Paulo, A Platéia e Diário Nacional, para mencionar alguns dos títulos mais importantes do país. O apoio emprestado por importantes órgãos da imprensa à Aliança Liberal pode ser tomado como um índice do desgaste do sistema político vigente (LUCA, 2008, p.166-175).

Já os periódicos identificados com a chamada velha ordem" foram alvo da fúria popular e tiveram suas sedes invadidas e depredadas. Veículos foram fechados ou empastelados, e, em alguns casos, ainda tinham seus dirigentes presos ${ }^{6}$.

Os proprietários das empresas jornalísticas, ainda que apoiando as medidas do governo, eram vigiados de perto, com censores instalados nas redações. No Estado Novo, o fundamental para a construção de uma identidade nacional foi a inclusão dos trabalhadores; para a consolidação desta identidade, a ação dos meios de comunicação foi decisiva. Para a eficácia da política e o projeto cultural desse regime, com o propósito de difundir uma imagem positiva, houve a subordinação dos meios de comunicação de massa ao Executivo.

Foi criado o Departamento de Imprensa e Propaganda (DIP), em 1939, por meio do Decreto de Lei n ${ }^{\circ} 1915$, de 27 de dezembro. Além de controlar tudo que era divulgado nos jornais, também contribuía para a difusão da ideologia "estadonovista". Como Vargas não possuía um partido político organizado para servir-lhe como base, o DIP se encarregaria de centralizar, coordenar e superintender a propaganda nacional divulgando assim seus ideais de governo "à moda Vargas.

Antes do DIP, havia sido criado o Departamento de Propaganda e Difusão Cultural (DPDC), em julho de 1934, e ligado ao Ministério da Justiça. Era o responsável pela censura do cinema na época.

As medidas adotadas pelo novo governo refletiram, sobretudo, na esfera estadual. Com o controle dos Estados, o poder central instaurou tais medidas de

6 "O Diário de Notícias e o Diário Carioca inicialmente apoiaram a Aliança Liberal e a Revolução de 1930, mas, após romperem com o governo em 1932, sofreram rigorosa censura (BARBOSA, 2007, p. 122). Na capital federal, também sofreram: O País, Gazeta de Notícias, A Noite e o Jornal do Brasil; em São Paulo, o Correio Pauslitano, A Gazeta e as Folhas da Manhã e da Noite (LUCA, 2008, p. 166). 
maneira a causar trágicas consequências. Além do DIP, nos Estados também foram implementados órgãos cuja função era praticamente a mesma do DIP, os Departamentos Estaduais de Imprensa, DEI (SODRÉ, 1999).

A Revolução de 1930 impôs a mordaça ao direito da liberdade de expressão e trouxe prejuízos a jornalistas e a empresas de comunicação. Atividades importantes da imprensa foram prejudicadas, por exemplo, a caricatura, que entrou em decadência após o surgimento do DIP.

Se por um lado a imprensa sofreu represálias e danos em sua estrutura, por outro, alguns jornais também se beneficiaram corrompendo-se com os ideais do Estado Novo. Com a pressão exercida sobre a profissão para a proliferação da ideologia "estadonovista", os profissionais e/ou donos de jornais tinham apenas duas opções: pagar o preço de agir corretamente indo contra o regime político vigente e de acordo aos princípios " sobretudo éticos " do jornalismo ou corromper-se com as propostas do "getulismo" extremamente desfavoráveis aos ideais da profissão de jornalista.

Apesar da luta e resistência de alguns jornalistas da época, outros tantos acabaram compactuando com o Governo em virtude das vantagens oferecidas às redações por meio de financiamentos específicos para esta finalidade. As verbas oficiais engordam as receitas de jornais e revistas, agências de notícias, emissoras de rádio. Subsídios ao papel e à importação de equipamentos gráficos favorecem os que colaboram com o poder" (BARBOSA, 2007, p.121).

Além de financiamentos especiais oferecidos pelo Governo a jornalistas, a classe podia desfrutar também de algumas regalias em função da propagação dos ideais "estadonovistas", como a isenção de Imposto de Renda.

Como a Era Vargas começou sem um partido político organizado, o "getulismo" se viu sem muitas alianças e procurou firmar parcerias das mais diversas possíveis a fim de consolidar seus ideais centralizadores. A Igreja Católica foi uma delas. Vargas percebeu a importância da Igreja como garantia simbólica da ordem e como instituição capaz de atrair setores que não estavam sob sua influência (MACIEL, 2007, p.7).

Pôde-se evidenciar demasiadamente o reflexo nos Estados das medidas adotadas nesse período. Com a derrubada da Velha República, a política baiana ia se alterar por completo com as mudanças impostas pela nova ordem política, com Vargas à frente. A Bahia passou a ser governada por interventores federais (RIBEIRO, 2012, p.16-17).
A imprensa baiana, como a dos demais estados, também sofreu perseguições. A Tarde, fundada por Ernesto Simões Filho em 15 de outubro de 1912, hoje o mais antigo jornal impresso baiano em circulação, seria o mais visado. Centenas de jovens profissionais foram presos ou banidos do território nacional (MORAES, 2005, p. 89, apud MATTOS, 2005, p. 103).

\section{Criação da ABI, ações e formação de jornalistas}

Foi nesse contexto de censura que surgiu, na Bahia, uma associação de imprensa. Nos discursos da própria instituição e seus representantes, foi criada pela necessidade de a categoria dos jornalistas se organizar com finalidades diversas, entre elas a fiscalização e repressão a atos de censura a que os profissionais eram subordinados (ABI, 2000).

Idealizada por 94 profissionais atuantes da época, foi criada com a presença de 73 jornalistas, nos salões da Associação Tipográfica Baiana. Foi destaque nas manchetes dos principais veículos de comunicação impressos no dia seguinte ao da sua fundação: no $A$ Tarde, no Diário de Notícias e no Diário da Babia (ABI, 1980, p. 19).

A ABI teve seis presidentes: Altamirando Requião, Ranulpho de Oliveira, Jorge Calmon, Afonso Maciel Neto, Samuel Celestino e Walter Pinheiro. Na avaliação do atual ${ }^{7}$, Antônio Walter Pinheiro, que assumiu esse cargo em 2011 e é também diretor-presidente do jornal Tribuna da Babia, um motivo de estímulo e de impulso para a criação da ABI foi a necessidade de a imprensa baiana de se posicionar e se fortalecer diante do poder e do domínio que a Igreja Católica exercia sobre os jornais, mas sem enfrentamentos diretos com o Governo. É nesse contexto que a ABI começa a atuar, segundo ele, construindo e propagando seus ideais fundamentados, acima de tudo, na liberdade de imprensa.

Na época em que a ABI foi fundada, além do $A$ Tarde, havia outros jornais em circulação de extrema importância para a imprensa baiana. Circulavam em Salvador, dentre outros: A Época; Era Nova; Fôia dos Rocêro, [...] Única, revista fundada em 1919, por Amado Coutinho; a revista $A$ Máscara, além dos já citados Diário de Notícias, A Tarde, Diário da Babia, O Imparcial, A Babia (SOUZA, 2005, p. 86).

Por ainda estar se firmando com a categoria dos profissionais, nessa década a $\mathrm{ABI}$ teve um viés mais institucional. Por meio da análise do clipping sobre a ABI “ que mostra o que foi veiculado na mídia baiana sobre a instituição ", identificou-se sua participação, na maioria

7 Entrevista de Walter Pinheiro em 12 de dezembro de 2013, na sede do Tribuna da Babia, em Salvador - BA. 
dos casos - principalmente no $A$ Tarde e na Revista Única “, em ações voltadas para a categoria. Convocações para reuniões, eleição de novos membros para diretoria, comemorações ao Dia da Imprensa (inclusive, promoveu a primeira comemoração da data na Bahia em 10 setembro de 1930) e reunião de membros para aprovação de estatuto estavam entre os destaques dos noticiários quando se referiam a $A B I$.

Esse período que a imprensa foi obrigada a vivenciar ajudou-a a desenvolver resistência contra as pressões oficiais. "Das prisões e dos processos que retiram jornalistas da circulação por ordem do governo que nasce uma imprensa mais consciente do seu papel, mais resistente às pressões oficiais" (BAHIA, 2009, p. 211).

Durante o período republicano e a chamada Era Vargas (1930-1945), os meios de comunicação passaram pelos mais diversos processos de sujeição e controle. Por mais de meio século, a ideia de uma imprensa livre foi uma ficção. O novo regime implantado em 1889 continuou com as práticas de corrupção e violência vindas do Império. Somente com a Revolução de 1930 o panorama mudou com a implantação de organismos burocratizados de controle e propaganda. Com a ditadura de 1937, uma nova onda de violência ocorreu, em um nível que só seria suplantado pela ditadura militar e, mesmo assim, após 1968 (SOUZA, 2003, p. 219 apud FREDERICO, 2007 , p. 3).

Sob a bandeira de defesa dos valores da profissão, sobretudo, da liberdade de imprensa, a ABI manifestou apoio a jornalistas que tinham sua liberdade de expressão cerceada na década de 1930, quando o país vivia a Ditadura, além de ter manifestado apoio às famílias de jornalistas mortos em decorrência das práticas de censura da época.

Em 1931, se deparou com o caso do jornal $O$ Imparcial, em que seu diretor, Mário Monteiro, foi preso acusado de excesso de liberdade nas reportagens veiculadas no jornal sobre temas policiais. Além da prisão, o impresso foi proibido de circular por período indeterminado. Embora a Associação Bahiana de Imprensa fosse recém-surgida e houvesse divergências no que tangia ao apoio nesse caso, a diretoria tomou providências e se fez presente agindo em favor do companheiro acusado para agilizar o processo da soltura do jornalista Mário Monteiro. O jornal que desaparecera em 12 de julho de 1930 voltou a circular no dia 10 do mês seguinte.

Mas a luta pela liberdade de imprensa é antiga e está no cerne do desenvolvimento do jornalismo como um todo. Começa com a luta contra a censura de um po- der político absoluto, sob forma de monarquia na esmagadora maioria dos países. Ela é de suma valia para a consolidação do jornalismo. Para Traquina (2005), a opinião pública era importante como instrumento de controle social. Era somente com a intervenção da imprensa que a população seria ouvida. Desse modo, os cidadãos tinham nos veículos de comunicação a maneira de expressar suas queixas e contestações pessoais, além de terem como se assegurar contra o poder vigente.

Com a consolidação dos ideais democráticos, a imprensa poderia exercer, de fato, um duplo papel na sociedade: além de serem porta-vozes do povo, atuariam também como vigilantes do poder político, protegendo os cidadãos contra abusos dos governantes. Com isso, a liberdade de imprensa se tornaria necessária e até mesmo indispensável à prática jornalística.

A criação de associações e sindicatos fez parte do processo de legitimação e do fortalecimento do jornalismo como profissão e começou a partir da segunda metade do século XIX, nos Estados Unidos e na Europa. Foi uma forma de promover a profissionalização, que envolveu também a criação de cursos universitários e instituição de códigos deontológicos (TRAQUINA, 2004, p.81 e 92).

$\mathrm{Na}$ Bahia, a ABI se engajou também em oferecer assistência jurídica e médica à categoria e no estímulo à criação de um curso de Jornalismo no Estado. Em agosto de 1939, já se cogitava a implantação de assistência médica e dentária e especulava-se a aquisição de matéria-prima para impressão de jornais em um sistema de cooperativa, além da criação de uma Escola de Jornalismo em Salvador (ABI, 1980, p. 34). Mas só 40 anos depois de sua fundação, na década de 1970, é que finalmente assinou um convênio de assistência médica a seus sócios e dependentes diretos, com dez clínicas da cidade de Salvador.

Já a assistência jurídica era um serviço de parceria com a Ordem dos Advogados do Brasil (OAB-BA), que mais tarde seria oficializado para atender a demandas que surgiram, inclusive, na década de 1990, pós-ditadura (período em que o Estado da Bahia viveu uma onda de assassinatos a jornalistas).

Para o primeiro presidente da ABI, Altamirando Requião (gestão de 10/09/1930 a 10/09/1931), a meta maior e o sonho que infelizmente não viu realizar na sua gestão - devido ao curto período em que esteve como presidente e à situação política vivida pelo país, como a Revolução de 1930 e os cerceamentos às liberdades individuais -, era a consolidação de uma sede definitiva da entidade. 
Durante algum tempo a $\mathrm{ABI}$ contou com a boa vontade da Associação Tipográfica Baiana e da Associação dos Empregados no Comércio da Bahia e até da Imprensa Oficial para realizar as suas reuniões e manter uma estrutura mínima de secretaria. Essa condição fortaleceu a ideia lançada por Requião, em 12 de setembro de 1930, de construir a Casa do Jornalista (CADENA, 2012).

Mas sua gestão foi de apenas um ano, pois Requião renunciou o cargo alegando motivos de saúde. A meta da sede própria só viria a se realizar no mandato do segundo presidente, Ranulpho de Oliveira. Durante sua gestão, a ABI foi reconhecida como de utilidade pública, em 27 de março de 1931, por meio do decreto estadual $\mathrm{n}^{\circ} .7336$.

Inúmeras doações foram concedidas à entidade para a construção da "Casa do Jornalista" (atual sede da ABI, situada na Praça da Sé, no centro da capital baiana). As agências bancárias estatais - CEF e Banco do Brasil - contribuíram com valores em dinheiro (ABI, 1980, p. 39).

Além de bancos, jornalistas e cidadãos de grande representação social no Estado se solidarizaram com a campanha de construção da sede própria da ABI e apoiaram o movimento de arrecadação de fundos como a Bolsa de Mercadorias e Valores do Estado da Bahia, que ofertou a quantia de 5.000 cruzeiros; também houve apoio da prefeitura da capital baiana, prefeituras de municípios do interior do Estado - como Jequié, Santo Antônio de Jesus, Itaparica e Mutuípe - e de outros voluntários que fizeram doações contribuindo, dessa forma, para a futura consolidação da sede (ABI, 1980, p. 62).

A "Casa do Jornalista" só foi inaugurada de fato, no dia 10 de setembro de 1960, no mandato de Ranulpho de Oliveira, que durou 39 anos (10/09/1931 -23/07/1970). Demorou, portanto, 30 anos para a concretização do sonho do primeiro presidente da ABI.

Após as gestões de Requião e Ranulpho de Oliveira, quem assumiu a presidência da ABI, em 10 de setembro de 1970, foi o jornalista Jorge Calmon Diniz de Bittencourt - à época redator-chefe do $A$ Tarde. Nascido em 7 de julho de 1915, em Salvador, trabalhou no $A$ Tarde durante 67 anos -47 deles como redator-chefe. Pela atuação no jornalismo baiano, Calmon recebeu diversas homenagens, como o título de Membro Benfeitor, que lhe fora concedido pela Academia de Letras da Bahia, do qual foi membro.

Por ter atuado na profissão durante muito tempo em $A$ Tarde, sua trajetória, na maioria das vezes, é associada ao jornal. Como relatou o próprio impresso em uma matéria sobre a morte do jornalista, em 2006:
Sua história se confunde com a do jornal ao qual se dedicou durante toda sua vida profissional. Começou a carreira de jornalista em 1935, como repórter de Assuntos Gerais. Passou pelas funções de redator, secretário de redação e, após 14 anos, assumiu o cargo de redator-chefe. Em 1971, ocupou o cargo de diretor redator-chefe. Antes, foi diretor da Biblioteca Pública da Bahia, de 1930 a $1942 .{ }^{8}$

Bacharel em Direito, atuou como professor no primeiro curso de jornalismo da UFBA, além de ter participado da organização e implantação do atual curso de Jornalismo dessa universidade. Jorge Calmon também foi deputado estadual, secretário do Interior e Justiça e ministro do Tribunal de Contas do Estado.

Apesar da curta estada na ABI (10/09/1970 - 10/09/1972), desenvolveu ações voltadas para a categoria dos jornalistas. Em 1971, por exemplo, firmou um convênio entre a ABI, o Sindicato dos Jornalistas e o Palace Hotel, para que os associados das duas entidades tivessem desconto de $20 \%$ nas refeições realizadas no hotel.

No mesmo ano enviou uma carta ao Comandante da VI Região Militar explanando sobre o tratamento dado à imprensa da Bahia em comparação à imprensa do Sul do país, com relação a determinadas notícias que eram consideradas nocivas à segurança nacional.

Conseguiu angariar verbas na busca por manter a casa equilibrada financeiramente: "Jorge Calmon comunica à Diretoria da $\mathrm{ABI}$ ter sido a entidade contemplada pelo Ministério da Educação e Cultura, no presente ano, com Cr\$11.000,00, e pelo Ministério de Planejamento com Cr\$15.000,00 verbas que serão em breve liberadas" (ABI, 1980, p. 94).

De posse da ABI, a Casa de Ruy Barbosa ${ }^{9}$ teve seu prédio restaurado em sua gestão; a necessidade de reparos nas instalações ocorreu devido as chuvas do mês de abril de 1971. Em agosto de 1972 - penúltimo mês de sua gestão -, a ABI assinou o convênio de assistência médica citado anteriormente. Através do convênio, inicialmente com duração de um ano, os beneficiados teriam um desconto de 30\% nas consultas. No mês se-

8 "Morre o jornalista Jorge Calmon", matéria publicada no $A$ Tarde On Line, em 18/12/2006. Disponível em http://atarde.uol.com.br/ noticias/711229. Acesso em 18 de fevereiro de 2014.

9 Situada no Centro Histórico de Salvador, a Casa de Ruy Barbosa mantém um museu dedicado à memória do grande jurista baiano Ruy Barbosa, contendo seus objetos pessoais e publicações e é administrada pela ABI em parceria com a Faculdade Ruy Barbosa. 
guinte, em 10 de setembro, Calmon abdicou do cargo afastando-se para assumir a chefia da Casa Civil do Governo Lomanto Júnior.

No mesmo ano, o jornalista Afonso Maciel Neto assumiu a Presidência da ABI, cargo que ocupou por 14 anos (1972 a 1986). Na época era diretor da Rádio Excelsior da Bahia. Na sua extensa gestão, deu continuidade às metas da entidade. Preocupado com a formação profissional, firmou parcerias com a UFBA e desenvolveu cursos e seminários não somente na capital como também no interior do Estado, para capacitação dos que atuavam no jornalismo. ${ }^{10}$

Em sua gestão, Afonso Maciel, além de fomentar eventos visando a capacitação dos profissionais sobre diversos aspectos do jornalismo, inseriu a $\mathrm{ABI}$ no abaixo -assinado idealizado por estudantes da UFBA, que visava a aquisição de melhorias para a instituição de ensino. Inaugurou também a Biblioteca de Comunicação Jorge Calmon, em setembro de 1973, que recebeu doações de periódicos. $\mathrm{Na}$ ocasião de inauguração, participaram autoridades soteropolitanas e o então governador do Estado, Antônio Carlos Magalhães (ACM).

No âmbito de seminários e cursos realizados, vale destacar o Seminário de Jornalismo Comparado realizado no ano seguinte, idealizado pela ABI e planejado e executado em parceria com a UFBA, Sindicato de Jornalistas do Estado da Bahia, Aliança Francesa e Instituto Cultural Brasil-Alemanha. Foi realizado no auditório da Bibliote-

10 A pauta de promover capacitação aos profissionais da imprensa também era uma prioridade da ABI brasileira. Isso em função do jornalismo ter passado por um processo de profissionalização no Brasil a partir do avançar da segunda metade do século XX, que ganhou força a partir do Decreto-Lei $n^{\circ}$ 910, de 30 de novembro de 1938, com o registro obrigatório dos jornalistas profissionais no Ministério do Trabalho. Ele dispôs sobre as condições de trabalho nas empresas jornalísticas e criou as escolas de jornalismo, estabelecendo a exigência do diploma para o exercício da profissão. Apesar da legislação, os salários eram, em geral, pagos com atraso, predominando o sistema de vales. Mesmo com esses problemas, o jornalismo era uma profissão com um certo prestígio social. Muitas vezes era utilizada para ascensão social e obtenção de poder, emprego público ou para seguir carreira política. Devido à má remuneração, a formação cultural dos profissionais, sobretudo dos repórteres, era em geral ruim. Havia, no entanto, uma elite de jornalistas bem preparados, geralmente formada nas Faculdades de Direito, mas a maioria não tinha sequer concluído o ensino médio. Alguns eram oriundos também das escolas de Medicina e Engenharia. A criação do ensino superior só vai se efetivar anos depois do decreto de 1938, que sofreu uma grande resistência patronal. Além disso, o governo federal, apesar de assumir o compromisso de patrocinar cursos, transferia a responsabilidade para os governos estaduais, que nada faziam, tendo em vista sua situação econômica. $\mathrm{O} 1^{\circ}$ curso regular do País acabou sendo montando pela iniciativa privada, na Fundação Casper Líbero. Vinculado à Faculdade de Filosofia, Ciências e Letras São Bento, da PUC de São Paulo, e autorizado pelo Decreto n 23.087, de 19 de maio de 1947 (RIBEIRO, 2007; BAHIA, 2000). ca Central, com programação com várias palestras, entre elas a do jornalista Mino Carta, que falou sobre "A censura e a linguagem subjetiva" (ABI, 1980).

Foi na gestão de Maciel que surgiu o prêmio de reportagem Associação Babiana de Imprensa idealizado com o intuito de premiar os melhores trabalhos desenvolvidos por jornalistas baianos. Para a avaliação dos trabalhos, havia um júri integrado por membros da entidade, do Conselho de Cultura, da Academia de Letras da Bahia, da Escola de Biblioteconomia e Jornalismo e do Sindicato de Jornalistas.

$\mathrm{Na}$ tentativa de ampliar a defesa pela liberdade de imprensa para o interior do Estado, criou a ABI Norte, uma seccional que funcionou em Juazeiro; em 13 de setembro de 1983, completou um ano de existência, mas não vingou por muito tempo. As seccionais existiam para tomar providências nos casos envolvendo jornalistas nas regiões de sua abrangência. Isso em uma época em que a comunicação era difícil. Com o avanço tecnológico, essa situação mudou.

Outro destaque da gestão de Maciel foi a atuação de uma jornalista mulher na presidência da $\mathrm{ABI}$ Regional Sul, a jornalista Jane Katia Badaró Santos.

Em 1986, assumiu a presidência da ABI Samuel Celestino. Natural de Itabuna, cidade do sul Bahia, ele ingressou no curso de Direito em Salvador aos 18 anos de idade e, aos 21, no Jornal da Babia. Sua ligação com as letras aflorou-se quando, junto a alguns colegas da Faculdade de Direito, desenvolveu um jornal intitulado $O$ Debate.

Em uma época em que não havia curso de jornalismo na Bahia ${ }^{11}$, Celestino ingressou no jornal na condição de "foca", permanecendo durante cerca de quatro meses sem receber remuneração pelo cargo. Era comum, na época, quem exercia o jornalismo ter formação acadêmica de Direito, a exemplo de Glauber Rocha, João Ubaldo Ribeiro e João Carlos Teixeira Nunes.

Após a fase probatória na profissão, foi contratado como repórter de um caderno especial. Embora tenha trilhado carreira no jornalismo, se formou em Direito em 1967 e advogou durante um ano, conciliando, durante nove meses, as funções de advogado e jornalista do Jornal da Babia. Dez anos depois de ter entrado no $A$ Tarde, se associou a $\mathrm{ABI}$. Foi reeleito várias vezes pre-

$11 \mathrm{Na}$ Bahia, o curso superior em Comunicação foi implantando em 1949, na Faculdade de Filosofia, na Universidade Federal da Bahia (UFBA), e transferido em 1968 para a Escola de Biblioteconomia e Comunicação (EBC) durante o regime militar e, depois, logrou certa independência relativa com a conquista de um espaço destinado à Faculdade de Comunicação (Facom), reconhecida oficialmente pelo reitorado em 1987 (BOTELHO, 2010). 
sidente e cumpriu 12 mandatos consecutivos, permanecendo 24 anos a frente da entidade.

Durante sua gestão, realizou um trabalho de abertura da $\mathrm{ABI}$ à comunidade e aos jornalistas de modo geral. Relatou sobre suas contribuições ${ }^{12}$ :

Meu primeiro trabalho foi abrir a Associação Bahiana. A entidade, que era apenas para a elite do jornalismo baiano, eu abri para todos os jornalistas, fiz uma aliança com o Sindicato dos Jornalistas Profissionais do Estado da Bahia; comecei por aí e em termos de gestão, eu fiz logo no primeiro ano do segundo mandato o auditório da ABI que hoje leva meu nome.

Entre as ações voltadas para estrutura física das instalações da ABI, Celestino - durante a reconstrução do Centro Histórico realizada por ACM - solicitou ao Governo do Estado uma reforma no prédio da ABI, levando em conta, na época, a importância arquitetônica do edifício.

No que tangia à liberdade de imprensa, idealizou um movimento contra as agressões a jornalistas - atos que eram frequentes na década de 1990, principalmente no interior do Estado. A ABI recebeu a visita de dois jornalistas franceses para avaliar o que estava acontecendo no Estado. Nesse contexto, deu seguimento à parceria com a OAB-BA para investigar e acompanhar casos de violência que os jornalistas sofriam. Sobre essa parceria, contou:

Nós fizemos uma parceria com a OAB e mantivemos esta parceria que era montada da seguinte forma: quando havia alguma ameaça ao jornalista no exercício da profissão, nós comunicávamos à $\mathrm{OAB}$ que verificava no município que acontecia o fato quais advogados que exerciam e acertava com eles para ver quem iria abraçar a causa. Além dos honorários, nós dávamos visibilidade a estes advogados, à medida que divulgávamos os casos na imprensa baiana. Esta parceria continua até hoje.

12 Entrevista de Samuel Celestino concedida em 28 de janeiro de 2014, na sede do Babia Notícias, em Salvador.
Celestino participou de discussões e movimentos em prol da sociedade soteropolitana e baiana. Manifestou apoio ao Movimento "A Cidade é Nossa", que cobrava projetos e uma reforma urbanística para a cidade de Salvador, com a participação de 60 entidades.

\section{A ABI na contemporaneidade}

A ABI atualmente não está tão presente na vida profissionais da área no sentido de tê-los participando efetivamente da instituição como a atual diretoria gostaria. O atual presidente Walter Pinheiro informou que são 325 associados, entre eles, 38 são conselheiros da Executiva, mas também as seccionais de Ilhéus, que cobrem a região sul da Bahia, a de Feira de Santana, e a Assembleia Geral composta por presidente e vice-presidente, secretário e três suplentes.

Para o $1^{\circ}$ vice-presidente da ABI, Ernesto Marques, "o fato é que as pessoas ainda a vêem muito mais como uma extensão do jornal $A$ Tarde ou como uma instituição muito mais vinculada aos empresários do jornalismo impresso do que uma casa com características mais amplas". ${ }^{13}$

Tais impressões se instauraram, segundo ele, em função de, por muito tempo, a Associação ter seguido sem renovação da diretoria - com a direção ocupada por jornalistas do $A$ Tarde. Desse modo, causou-se um esvaziamento progressivo, em que muitas pessoas deixaram de ter interesse em participar porque perderam de vista a perspectiva de pretender integrar ou presidir a diretoria.

Em sua avaliação, com o tempo, as pessoas foram ampliando cada vez mais a ideia de que a $A B I$ era comandada pelo $A$ Tarde, por Jorge Calmon e que não adiantava se mobilizar para fazer algo pela Associação. Com isso, os membros deixaram de frequentá-la estimulando as gerações mais novas de jornalistas a ignoraremna.

Com a perda acentuada de frequentadores, Marques ressalta a mobilização que as últimas gestões têm feito para recuperar os profissionais da categoria. "A Associação tem feito um esforço enorme, há alguns anos para que os profissionais voltem a se sentir representados, haja vista que com o tempo houve um forte distanciamento".

Sobre este processo, o jornalista Sérgio Mattos ${ }^{14}$, pela segunda vez consecutiva no cargo de $2^{\circ}$ vice-presidente da $\mathrm{ABI}$, afirma que, no início, a $\mathrm{ABI}$ surgiu como

13 Entrevista de Ernesto Marques na sede da ABI em 22/11/2012. 14 É professor da UFRB, pesquisador e escritor de livros da área de comunicação, e superintendente da Editora da UFRB. Na ABI, já foi presidente da Assembléia Geral por dois mandatos e Diretor Cultural. Concedeu depoimento por e-mail em 19/03/2014. 
órgão patronal e era dirigida por diretores dos veículos impressos e de outros associados. Com o tempo houve uma maior participação dos empregados, professores e pesquisadores da mídia, que hoje formam o grosso dos associados:

A ABI pode ser considerada uma Instituição forte politicamente e respeitada na sociedade, e, portanto, tem potencial para participar e liderar determinados debates, pois possui representatividade na sociedade para tal. Contudo, ainda falta recuperar a representatividade nos próprios meios de comunicação, entre os jornalistas, publicitários, radialistas e empresários, trabalhadores etc. Esse é um esforço que a atual diretoria vem empreendendo.

A instituição, que se mantém do aluguel de seus imóveis, tem como desafio, portanto, ampliar seu quadro de associados até para renovar futuramente sua diretoria. $\mathrm{Na}$ atual, Marques é o membro mais jovem - com 28 anos de profissão.

A preocupação da diretoria é para que haja uma ocupação maior dos jornalistas na Associação. "Acho que isso deve acontecer com as próximas gerações; os antigos já têm suas rotinas e acabaram não se envolvendo", avaliou Walter Pinheiro, acrescentando que a sede da $\mathrm{ABI}$ no centro histórico teria como ponto negativo o fato de não dispor de estacionamento, embora quando promove eventos tenha uma grande participação não necessariamente de jornalistas.

O maior fluxo de visitação à sede da $\mathrm{ABI}$ é de estudantes de Arquitetura - em virtude da riqueza arquitetônica de seu prédio no centro histórico de Salvador - e por estudantes de História, uma vez que possui vasto acervo com acesso e condições confortáveis para pesquisa. Ainda há pouco interesse por parte dos estudantes de Jornalismo em frequentá-la.

O investimento no resgate da importância da Associação tem se dado por meio de debates promovidos pela casa, no que tange à defesa da liberdade de imprensa, sobre a cidade de Salvador, sobre temas de interesse do Estado, mais especificamente sobre a recuperação do Centro Histórico da cidade, da preservação do patrimônio - temas que a atual gestão tem se dedicado mais, no sentido de mobilizar os diretores e pouco a pouco atrair mais pessoas para a sede da ABI.
A ABI fez uma reforma em 2011 em sua sede, onde houve mudanças na estrutura do espaço a fim de oferecer maior comodidade aos associados e visitantes.

Dispõe de uma sala de exibição cinematográfica, chamada Roberto Pires (em homenagem ao cineasta baiano), voltada para estudiosos da área de cinema e audiovisual, e de espaços que contribuem para o processo de amadurecimento profissional da classe, como a biblioteca Jorge Calmon - que possui acervo especializado em comunicação englobando materiais sobre teoria da comunicação, jornalismo, semiologia, técnica de história em quadrinhos, propaganda, publicidade, marketing, relações públicas, fotografia, cinema, radiodifusão, televisão, além de biografias de atores e cineastas.

Ernesto Marques destacou que a reforma da sede representou um avanço, pois a atual diretoria conseguiu estabelecer um padrão moderno e confortável para a biblioteca e manter a preservação do acervo. A reforma da biblioteca se deu início justamente com a higienização e restauro dos documentos.

Outra ação em andamento é a digitalização do acervo que a $\mathrm{ABI}$ possui - cerca de 100 mil páginas de jornais dos séculos XIX e XX, livros raros (que não se encontram em nenhuma outra biblioteca do Brasil) e fotografias.

O auditório Samuel Celestino, localizado no $8^{\circ}$ andar do Prédio Ranulfo Oliveira, é por onde passam diversos assuntos da contemporaneidade que são discutidos com a participação da ABI. Também possui o Museu de Imprensa, que funciona no próprio prédio e tem como objetivo preservar a história da imprensa baiana. Nele, os visitantes encontram periódicos antigos, obras e objetos pessoais de jornalistas.

\section{Conclusões}

Embora não exista um sistema federativo que reúna as associações de imprensa dos estados, a ABI baiana se coloca como "uma das mais representativas e combativas entidades de luta pela liberdade de imprensa, ao lado da Associação Nacional de Jornais (ANJ), a Federação Nacional dos Jornalistas (Fenaj) e a Associação Brasileira de Imprensa" (LENE \& LOPES, 2013).

Com as contribuições simbólicas que a ABI buscou empreender no campo da comunicação na Bahia, ela se estabelece como "uma casa de ideias, de debates e lutas pelo interesse coletivo". Portanto, tem preocupações com o que acontece além das redações e assessorias. Não integra apenas jornalistas, mas radialistas, publicitários e empresários e dirigentes de empresas de comunicação do Estado.

\section{3}


Os encontros realizados na ABI e fora de sua sede, mas com a participação de seus membros representando-a, reitera sua preocupação com os interesses da categoria profissional e da sociedade.

No intuito de acompanhar os avanços tecnológicos da era digital e do novo contexto midiático, a instituição se inseriu na plataforma web. Colocou no ar um site onde disponibiliza informações sobre a entidade, sobre como se associar, Estatuto da ABI, notícias relacionadas à imprensa, à liberdade de expressão, além de contar um pouco de sua história. Criou também uma página na rede social Facebook onde divulga suas ações e notícias.

Observa-se a atuação da ABI que, como a Associação Brasileira de Imprensa, tem como principal bandeira a defesa da liberdade, valor que está no cerne da configuração do jornalismo na democracia desde sua expansão no século XIX (TRAQUINA, 2004, p.33-54).

E o papel de representação da categoria empreendido pela ABI contra a censura e cerceamento das liberdades individuais, ainda na década de 1930, e mais recentemente nos anos 1990, na gestão de Samuel Celestino, quando voltaram a ocorrer ameaças e assassinatos a jornalistas na Bahia.

A atuação da $A B I$ não tem se restringido a questões ligadas à categoria profissional, mas também a assuntos que concernem à sociedade soteropolitana e baiana. Com o tempo, ela foi se envolvendo também em temáticas ligadas à sociedade civil, ampliando seu papel.

A criação de associações como a ABI contribuiu para o fortalecimento do jornalismo enquanto profissão, com ações como seminários, cursos e eventos voltados para a área, bem como a luta pela criação de cursos universitários de jornalismo como o da UFBA.

A ABI contribuiu na percepção dos interesses da categoria, funcionando também como espaço de sociabilidade, uma vez que vem realizando eventos e discussões frequentemente, contribuindo também, dessa forma, para o fortalecimento do campo da comunicação na Bahia.

Por ser voltada para a defesa dos jornalistas e da liberdade de imprensa, pode ser considerada importante simbolicamente para o campo do jornalismo, para o processo de profissionalização dos jornalistas e para aquilo que Barbie Zelizer (1993) chamou de uma "comunidade interpretativa" ou que Michel Maffesoli (1988) chamou de "tribo" (apud TRAQUINA, 2005, p.24).

O que é ser jornalista parte de toda uma cultura constituída por uma constelação de crenças, mitos, valores, símbolos e representações que constituem o ar que marca a produção das notícias. A identidade profissional, isto é, um ethos, é definida por uma maneira de como se deve ser (jornalista)/estar (no jornalismo) (TRAQUINA, 2004, p.37) .

Pôde-se perceber, portanto, que a $\mathrm{ABI}$ cumpre um papel simbólico importante na defesa dos valores que conformam o ethos jornalístico, e busca se renovar diante do contexto atual de novas tecnologias da informação e da comunicação.

A sua atuação continua pertinente e necessária em um país que ainda precisa avançar em sua democracia e que ocupa, por exemplo, o $3^{\circ}$ lugar no ranking das Américas em ataques à imprensa (atrás da Colômbia e do México) e a $11^{a}$ posição no índice mundial de impunidade contra crimes praticados contra jornalistas em represália direta por suas reportagens (COMITÊ DE PROTEÇÃO AOS JORNALISTAS, 2013).

Só para se ter uma ideia de quanto a questão ainda é preocupante em pleno século XXI, de acordo com relatório da Secretaria de Direitos Humanos da Presidência da República, ao menos 321 profissionais de imprensa sofreram alguma forma de agressão de 2009 a 2014, sendo 18 assassinados.

O valor da liberdade de imprensa continua em destaque na agenda internacional de debates acerca da profissão de jornalista e do jornalismo. E exige a participação e a atenção não só de associações de jornalistas como a ABI, mas de toda a sociedade civil para o problema social da violência.

\section{Referências}

\section{Fontes primárias}

CLIPPING DA ABI das décadas de 1970 a 1980. Acervo da ABI.

CELESTINO, Samuel. Entrevista em 28 de janeiro de 2014, na sede do portal Babia Notícias, em Salvador - BA.

MARQUES, Ernesto. Entrevista em 22 de novembro de 2012, na sede da Associação Bahiana de Imprensa (ABI), em Salvador " BA.

MATTOS, Sérgio. Entrevista em 19 de março de 2014.

PINHEIRO, Walter. Entrevista em 12 de dezembro de 2013, na sede do jornal Tribuna da Babia, em Salvador BA. 


\section{Fontes secundárias}

ASSOCIAÇÃO BAHIANA DE IMPRENSA. Cronologia da Associação Babiana de Imprensa 1930 - 1980. Salvador, 1980.

ASSOCIAÇÃO BAHIANA DE IMPRENSA. Um Marco na História da Imprensa Livre. - Salvador: CONTEXTO \& ARTE EDITORIAL, 2000.

BARBOSA, Marialva. História Cultural da Imprensa: Brasil, 1900-2000. Rio de Janeiro: MauadX, 2007.

História da Comunicação no Brasil. Petrópolis, RJ:

Editora Vozes, 2013.

; RIBEIRO, Ana Paula Goulart. O que a bistória pode legar aos estudos de jornalismo. Trabalho apresentado no Núcleo de Pesquisa de Jornalismo do XXVIII Congresso Brasileiro de Ciências da Comunicação, promovido pela Intercom e Uerj, nos dias 5 a 9 de setembro de 2005.

BAHIA, Juarez. História da imprensa brasileira - Jornal, história e técnica. Rio de Janeiro: MauadX, 5ª edição, 2009.

BAHIA, Juarez. Dicionário de Jornalismo século XX. Rio de Janeiro: Mauad X, 2010.

BOURDIEU, Pierre. Campo do poder, campo intelectual e habitus de classe. In: A Economia das Trocas Simbólicas. São Paulo: Perspectiva, 1999, p. 183-202.

. Sobre a Televisão - seguido de A influência do jornalismo e Os Jogos Olímpicos. Trad. Maria Lúcia Machado. Rio de Janeiro: Jorge Zahar Ed., 1 a edição, 1997, 144p.

BOTELHO, ALAN VEIGA. Ensino na Facom: Evolução e eficiência do curso de Jornalismo na UFBA. Trabalho de Conclusão de Curso. Disponível em: http://www.facom. ufba.br/portal/wp-content/uploads/2012/01/Ensinona-Facom-Alan-Botelho.pdf. Acesso em 12/03/2014.

CADENA, Nelson. A fundação da Associação Baiana de Imprensa. In: Memórias da Bahia, de 30 de agosto de 2012. Disponível em http://www.ibahia.com/a/blogs/memoriasdabahia/2012/08/30/a-fundacao-da-associacao -baiana-de-imprensa/. Acesso em 25/03/2014.

COMITÊ DE PROTEÇÃO AOS JORNALISTAS (CPJ). Brasil ocupa $3^{\circ}$ lugar em ataques à imprensa nas Américas. In: http://portalimprensa.uol.com.br/noticias/brasil/57855/. Acesso em 22 de abril de 2013.
DUARTE, Jorge e BARROS, Antônio (org.) Métodos

e Técnicas de Pesquisa em Comunicaşão. São Paulo: Editora Atlas, 2005.

FREDERICO, Renata Leite Raposo. A censura aos meios de comunicação no período ditatorial do Brasil e a história do jornalismo especializado em gastronomia. Trabalho apresentado no V Congresso Nacional de História da Mídia. Intercom, São Paulo, SP - 31/05 a 2/06/2007.

LENE, Hérica. Memória e História da Comunicação: a participação da ABI no processo de profissionalização do jornalista. In: Revista Brasileira de História da Mídia (RBHM), v.2. n.1, janeiro de 2013/junho de 2013, p.19 a 29.

LENE, Hérica; LOPES, Rafael. Memória e história da imprensa: as associacõoes profissionais e a conformação do ethos jornalístico. Trabalho apresentado no GP História do Jornalismo, no XXXVI Congresso Brasileiro de Ciências da Comunicação. Intercom, Manaus, AM - 4 a 7/9/2013.

LUCA, Tania Regina de. A grande imprensa na primeira metade do século XX. In: MARTINS, Ana Luiza \& LUCA, Tania R (orgs.). História da imprensa no Brasil. São Paulo: Editora Contexto, 2008, p.149-175.

MACIEL, Sandra Mara Pinheiro. A censura na música no Estado Novo (1937-1945). Monografia apresentada ao Departamento de História, do Setor de Ciências Humanas, Letras e Artes, da Universidade Federal do Paraná. Curitiba, 2007. Mimeo.

MARTINS, Ana Luiza \& LUCA, Tania R (orgs.). História da imprensa no Brasil. São Paulo: Editora Contexto, 2008, p.149-175.

RIBEIRO, Ana Paula Goulart. Imprensa e história no Rio de Janeiro dos anos 1950. Rio de Janeiro: E-Papers, 2007.

RIBEIRO, Carlos. Um século de jornalismo na Babia 2012 1912. Lauro de Freitas-BA: Solisluna Editora, 2012.

SANTAELLA, Lucia. Comunicação \& pesquisa - projetos para mestrado e doutorado. São Paulo: Hacker Editores, 2002, 216p.

SKIDMORE, Thomas E. Uma história do Brasil. 4.ed. São Paulo: Editora Paz e Terra, 2003.

SODRÉ, Nelson Werneck. História da Imprensa no Brasil. 4.ed. Rio de Janeiro: Mauad, 1999. 
SOUZA, Antônio Loureiro de. Apontamentos para a História da Imprensa na Bahia. In: TAVARES, Luis Guilherme Pontes (org.). Apontamentos para a História da Imprensa na Babia. Salvador: Academia de Letras da Bahia; Assembléia Legislativa do Estado da Bahia, 2005.

TAVARES, Luís Henrique Dias. História da Babia. 11.ed. São Paulo: Ed. da Unesp; Salvador/BA: EDUFBA, 2008.

TRAQUINA, Nelson. Teorias do Jornalismo, porque as noticias são como são. 2.ed. Florianópolis: Insular, 2005.

Recebido em: 30/01/2015

Aprovado em: 13/04/2015 